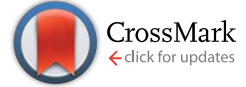

Cite this: J. Mater. Chem. A, 2015, 3 , 5572

Received 14th November 2014 Accepted 3rd February 2015

DOI: $10.1039 / c 4 t a 06186 a$

www.rsc.org/MaterialsA

\section{Phosphorus-carbon nanocomposite anodes for lithium-ion and sodium-ion batteries}

\author{
Thrinathreddy Ramireddy, ${ }^{2}$ Tan Xing, ${ }^{a}$ Md Mokhlesur Rahman, ${ }^{a}$ Ying Chen, ${ }^{a}$ \\ Quentin Dutercq, ${ }^{\text {ab }}$ Daniel Gunzelmann ${ }^{a}$ and Alexey M. Glushenkov ${ }^{\star a c}$
}

\section{Introduction}

Phosphorus is a non-metallic element, which is known to have three common allotropes - white, red and black. ${ }^{1}$ White phosphorus is volatile and unstable; it bursts into flames when it is exposed to natural atmosphere. Red phosphorus is usually amorphous in nature and is widely commercially available. Black phosphorus is a crystalline phase, thermodynamically stable below $550{ }^{\circ} \mathrm{C}$ and transforming to red (amorphous) phosphorus at higher temperature. ${ }^{\mathbf{1 , 2}}$ Among various applications, the use of phosphorus in anodes of lithium-ion and sodium-ion batteries attracts attention due to its high theoretical capacity (2596 mA h g ${ }^{-1}$ ). ${ }^{3}$ Specifically, red and black forms of phosphorus have been considered as candidates for anode materials. $^{4-11}$

In lithium-ion batteries phosphorus is considered as a possible high capacity alternative to the conventional graphitic anode (theoretical capacity of only $372 \mathrm{~mA} \mathrm{~h} \mathrm{~g}{ }^{-1}$ ). The theoretical capacity of phosphorus is much higher than that and is inferior only to $\mathrm{Si}\left(4200 \mathrm{~mA} \mathrm{~h} \mathrm{~g}{ }^{-1}\right)^{3,12}$ among the materials that can electrochemically alloy with lithium. Due to the limitations of electronic conductivity and significant volume changes upon

${ }^{a}$ Institute for Frontier Materials, Deakin University, Waurn Ponds, 3216 Victoria, Australia.E-mail: alexey.glushenkov@deakin.edu.au

${ }^{b}$ Université de Nantes, Polytech Nantes, Institut des Matériaux Jean Rouxel, CNRS, Rue Christian Pauc, BP 50609, 44306 Nantes Cedex 3, France

${ }^{c}$ Melbourne Centre for Nanofabrication, 151 Wellington Rd, Clayton, VIC 3168, Australia operation in a lithium-ion battery, the practical electrochemical performance of bulk red or black phosphorus has been found unsatisfactory, with either poor reversibility and Coulombic efficiency $^{4-6}$ or problematic cyclic stability. ${ }^{7}$ The current consensus opinion is that phosphorus-based battery anodes should be prepared in the form of nanocomposites in which the phosphorus component is finely dispersed in the carbon component. $^{4,5,8-11}$ Composites of amorphous phosphorus ${ }^{8}$ as well as red $^{4,9}$ and black ${ }^{5,8,10}$ crystalline forms with carbon have been demonstrated. Reasonably stable capacity retention over up to 100 cycles with high Coulombic efficiencies has been reported by Wang et al. ${ }^{\mathbf{1 1}}$ and Qian et $a .^{8}$ These two recent manuscripts claim the stable capacity in the phosphorus component of the composites in excess of $2000 \mathrm{~mA} \mathrm{~h} \mathrm{~g}^{-1}$, utilising 92.8 and $90.7 \%$ of the theoretical capacity of phosphorus, respectively. Sun et al. have suggested that the formation of stable $\mathrm{P}-\mathrm{C}$ bonds may be responsible for the stability of ball milled phosphorus-carbon nanocomposites in lithium-ion battery anodes. ${ }^{13}$

In sodium-ion batteries the anode materials conventionally considered for lithium-ion batteries such as graphite, Ge or $\mathrm{Si}$ are either inactive or able to display only small capacities. ${ }^{\mathbf{1 4}}$ As a result, $\mathrm{Sb}, \mathrm{Sn}$ and $\mathrm{P}$ have emerged as possible high-capacity anode materials operating via an alloying-dealloying mechanism. ${ }^{15-18}$ Among them, phosphorus has the highest theoretical capacity, which makes it a very interesting material to study. Recently, phosphorus has been tested as an anode for Na-ion battery. Kim et al. have estimated that amorphous red 
phosphorus-carbon composite could deliver a capacity of 1890 $\mathrm{mA} \mathrm{h} \mathrm{g}{ }^{-1}$ at a current rate of $143 \mathrm{~mA} \mathrm{~g}^{-1}$ (ref. 18) at a slightly elevated temperature of $30{ }^{\circ} \mathrm{C}$. Qian et al. have reported amorphous phosphorus-carbon composite with a capacity of 1750 $\mathrm{mA} \mathrm{h} \mathrm{g}^{-1}$ at a current rate of $250 \mathrm{~mA} \mathrm{~g}^{-1}$ at room temperature. ${ }^{19}$ Subsequently, Li et al. have prepared red phosphorus-carbon nanotube composite by hand grinding in an agate mortar, and the composite demonstrates an initial reversible capacity of $1530 \mathrm{~mA} \mathrm{~h} \mathrm{~g}^{-1}$ when tested at current density of $143 \mathrm{~mA} \mathrm{~g}^{-1} .^{20}$ The capacity was monotonously deteriorating upon cycling, in contrast to the previous report, ${ }^{19}$ in which deterioration initiated after the first 40 cycles of stable performance. Black phosphorus-carbon composites have not been studied much in conjunction with sodium-ion batteries, with only limited data presented in Supporting Information of paper by Qian et al. ${ }^{19}$ Phosphorus-based electrodes for sodium-ion batteries have also been assessed by Yabuuchi et al., ${ }^{21}$ and it has been revealed that adding fluoroethylene carbonate to the electrolyte is critical for the stability of phosphorus-based anodes.

Herein we present the synthesis of phosphorus-carbon nanocomposites and their systematic evaluation as lithium-ion and sodium-ion anode materials. The structural analysis indicates that the composites contain black (orthorhombic) phosphorus either in the form of crystalline nanoparticles or in significantly disordered state. Discussion of data and correlation with previously published results are presented. Phase changes in the electrode upon discharge and charge of lithium and sodium halfcells are analysed, and the structural integrity of phosphorusbased electrodes cycled within full $\left(2.0-0.01 \mathrm{~V} v\right.$ s. $\mathrm{Li} / \mathrm{Li}^{+}$or $\left.\mathrm{Na} / \mathrm{Na}^{+}\right)$ or restricted potential windows is studied. We expect that our results will stimulate further important developments of phosphorus-based anode materials for metal-ion batteries.

\section{Experimental}

\section{Material synthesis}

Red phosphorus powder (100 mesh, 98.9\% purity, Alfa Aesar) was used as a starting material. Black phosphorus was prepared by milling 6 grams of red phosphorus in a stainless steel jar using Fritsch Pulverisette 5 planetary ball mill for $25 \mathrm{~h}$ under Ar atmosphere (200 kPa excess pressure above atmospheric). The ball to powder ratio was $110: 1$ (ten balls with a diameter of $25.4 \mathrm{~mm}$ were used). Rotation speed was $200 \mathrm{rpm}$. The obtained black phosphorus was mixed with graphite (Sigma Aldrich, 282863, <20 $\mu \mathrm{m})$ in a $7: 3$ weight ratio and the mixture was milled in two types of ball mills. Phosphorus-carbon composite C-1 was produced by milling $6 \mathrm{~g}$ of the mixture for $25 \mathrm{~h}$ in Fritsch Pulverisette 5 planetary ball mill under the conditions similar to those used for preparing black phosphorus. Phosphorus-carbon composite C-2 was produced by milling $5 \mathrm{~g}$ of the mixture in a magneto-ball mill. ${ }^{22}$ Four stainless steel balls $(25.4 \mathrm{~mm}$ in diameter) were loaded into the vial, and the milling was conducted for $100 \mathrm{~h}$ at $160 \mathrm{rpm}$. The milling was performed under Ar atmosphere at a pressure of $100 \mathrm{kPa}$ above atmospheric in the presence of an external magnet at a $45^{\circ}$ position. The milling mode is similar to the ball milling mode $\mathrm{C}$ described in ref. 23. The ball to powder ratio in this experiment was $52.8: 1$.

\section{Characterization}

X-ray diffraction (XRD) patterns of materials and electrodes were obtained by using a PANalytical X'Pert Pro instrument with a Cu K $\alpha$ radiation source $(\lambda=1.54181 \AA)$. The XRD patterns were collected over the range of $20-80^{\circ}$ by keeping the step size of 0.02 at a scan rate of $2 \mathrm{~s}$ per step. The phases in the obtained patterns were analysed using X'Pert High Score Plus software. The cycled electrodes for the XRD analysis were covered with Kapton tape to prevent reacting with moisture and oxygen after being extracted from the lithium and sodium half-cells in an Arfilled glove box. The TEM characterization was done using a JEOL JEM-2100F instrument operated at $200 \mathrm{kV}$. Energy-filtered TEM (EFTEM) elemental maps were obtained using a Gatan Quantum ER 965 Imaging Filter and the three-window method.

Raman spectroscopic characterisation was performed using a Renishaw inVia micro-Raman system. A laser with $514 \mathrm{~nm}$ wavelength was used during the experiment. The power of laser was $2.5 \mathrm{~mW}$ ( $5 \%$ of max power) and the accumulation time was 60 s. $20 \times$ lens was used in the experiment. The final spectra were formed by accumulating two scans.

Solid-state NMR spectra were acquired using Bruker Avance3 300 and 500 spectrometers, operating at 7.05 and 11.4 T. All samples were handled and packed into standard zirconia magic angle spinning (MAS) rotors in a glove box with argon atmosphere. The samples of red and black $\mathrm{P}$ were packed into 2.5 mm MAS rotors, mounted into a triple resonance MAS probe and measured under magic-angle-spinning (MAS) at a speed of $32.5 \mathrm{kHz}$ and a resonance frequency of $202.4 \mathrm{MHz}$. Due to problems with achieving comparable spinning speeds the nanocomposite samples were packed into $4 \mathrm{~mm}$ zirconia MAS rotors and measured at $6 \mathrm{kHz}$ spinning speed at $121.5 \mathrm{MHz}$ resonance frequency. Spectra were acquired using a Solid-Echo pulse sequence with excitation frequencies of 102-143 kHz. All ${ }^{31} \mathrm{P}$ shifts are given relative to $85 \% \mathrm{H}_{3} \mathrm{PO}_{4}$ solution. The recycle delays were set to $4 T_{1}$, long enough to guarantee a full spin relaxation according to the $T_{1}$ relaxation time constants, which were measured independently for each sample. The spectrum of red $\mathrm{P}$ was acquired by sampling 64 scans with a recycle delay of 360 s. The spectrum of black $P$ was acquired by sampling 32 scans with a recycle delay of $40 \mathrm{~s}$. The spectrum of composite C-1 was acquired by sampling 64 scans with a delay of $3 \mathrm{~s}$. The composite C-2 was acquired by sampling 320 scans with $180 \mathrm{~s}$ recycle delay.

Scanning electron microscopy (SEM) imaging has been done with a Supra 55VP field emission scanning electron microscope. The accelerating voltage was $5 \mathrm{kV}$ and the working distance was about $5 \mathrm{~mm}$. An In-lens detector was used during the experiment to provide images with good signal/noise ratio. The electrodes for SEM imaging were extracted from lithium and sodium half-cells after cycling for a large number of cycles.

\section{Electrochemical characterization}

The composite materials were mixed with Super $\mathrm{P} \mathrm{Li}{ }^{\mathrm{TM}}$ (Timcal Ltd.) and sodium carboxymethyl cellulose (CMC) binder (in a weight ratio of $80: 10: 10)$ in de-ionized water to form a homogenous slurry. The slurry was then coated onto copper foil 
substrates and heated in vacuum overnight at $90{ }^{\circ} \mathrm{C}$. All electrodes had a standard size of $1 \times 1 \mathrm{~cm}^{2}$ and the weight of active material (phosphorus-carbon composite) was controlled in the range between 0.92 and $1.05 \mathrm{mg}$. Lithium and sodium half-cells were assembled in the form of CR2032 coin cells inside the Arfilled glove box (Innovative Technology, USA) using a CR2032 coin cell. $\mathrm{Li}$ and $\mathrm{Na}$ metal pieces were used as a counter electrodes. The electrolyte for lithium half-cells was $1 \mathrm{M} \mathrm{LiPF}_{6}$ in a $1: 1: 1$ (by volume) mixture of ethylene carbonate (EC), diethyl carbonate (DEC) and dimethyl carbonate (DMC). The electrolyte for sodium half-cells was $1 \mathrm{M} \mathrm{NaClO}_{4}$ in propylene carbonate (PC) with $2 \%$ fluoroethylene carbonate (FEC) additive. Polyethene separators (MTI Corp., USA) and Whatman GF/F microfiber glass separators (Sigma Aldrich) were used for lithium and sodium cells, respectively. The lithium half-cells were galvanostatically charged-discharged between 2.0-0.01 or 2.0-0.67 V vs. $\mathrm{Li} / \mathrm{Li}^{+}$at a current rate of $100 \mathrm{~mA} \mathrm{~g}^{-1}$ using LAND battery testers (Wuhan LAND Corporation, China). The sodium half-cells were galvanostatically charged-discharged between $2.0-0.01$ or $2.0-0.33 \mathrm{~V} v$ s. $\mathrm{Na} / \mathrm{Na}^{+}$using the same instruments. All capacities were calculated per total weight of the composites (including both phosphorus and carbon components).

\section{Results and discussion}

Black phosphorus used for the preparation of the composites was synthesized mechanochemically in our laboratory from commercially available red amorphous phosphorus, similarly to the previously used approach. ${ }^{5}$ Two phosphorus-carbon composites were prepared by high energy ball milling of mixtures of as-produced black (orthorhombic) phosphorus and graphite using two ball mills, a planetary one and a magnetoball mill. For the purpose of clarity, we refer to the composite prepared by the planetary ball mill as C-1 and the composite prepared by a magneto-ball mill as C- 2 .

\section{Characterisation of samples}

The XRD patterns of red and black phosphorus and the phosphorus-carbon composites are shown in Fig. 1. Red $\mathrm{P}$ is amorphous, as expected (Fig. 1a). Its XRD pattern is dominated by two broad humps at 25-38 and 47-65 degrees. In contrast, the XRD pattern of black $\mathrm{P}$ (Fig. 1b) displays a number of crystalline peaks, consistent with a standard powder diffraction file (JCPDS \#00-009-0020). Similar diffraction patterns for black phosphorus obtained by ball milling were reported previously by Park and Sohn. ${ }^{5}$ The composite $\mathrm{C}-1$ (Fig. 1c) retains the same crystalline nature of the phosphorus component that can be seen in Fig. 1b for the pure black phase. The phosphorus in the composite C-2 is clearly more disordered, displaying broad X-ray signals (Fig. 1d). A very weak increase in intensities around the positions of the three strongest peaks of the black orthorhombic P (highlighted with arrows) can, however, still be noticed, indicating that some nanocrystalline black $\mathrm{P}$ may remain in the composite. The graphitic peaks are not visible in the XRD patterns of either composites C-1 or C-2.

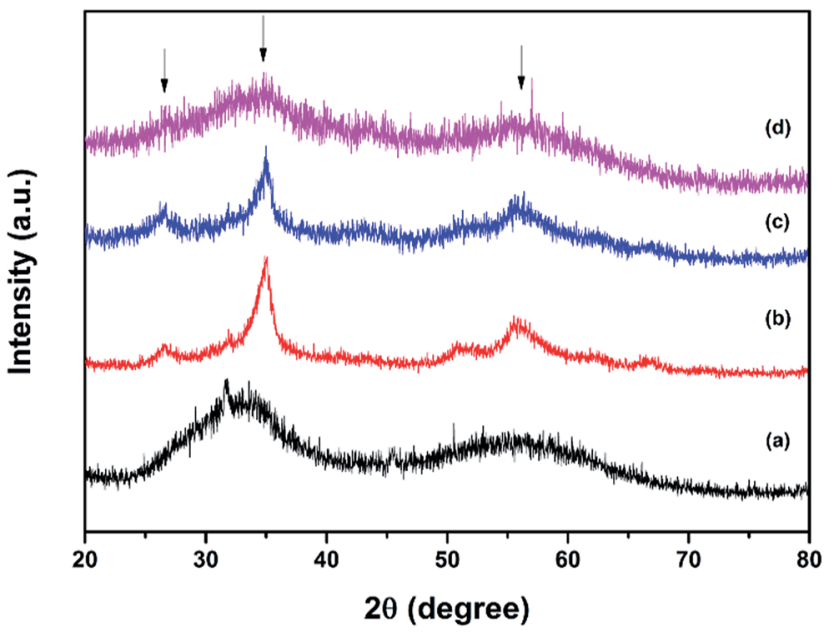

Fig. 1 X-ray diffraction patterns: (a) red $P$, (b) black $P$, (c) phosphoruscarbon composite $\mathrm{C}-1$ and (d) phosphorus-carbon composite C-2 (arrows indicate the positions of the strongest peaks of black phosphorus).

Fig. 2a shows the Raman spectra of the red phosphorus and mechanochemically obtained black phosphorus. The Raman signature of the red amorphous phosphorus is consistent with that in other reports. ${ }^{\mathbf{8 1 1 , 1 8}}$ After ball milling, three unambiguous Raman bands appear at about 363, 438 and $467 \mathrm{~cm}^{-1}$, which are the typical Raman fingerprints of black phosphorus ${ }^{7,13}$ corresponding to the $\mathrm{A}_{1 \mathrm{~g}}, \mathrm{~B}_{2 \mathrm{~g}}$ and $\mathrm{A}_{2 \mathrm{~g}}$ modes. These results are consistent with the XRD data and confirm that mechanochemical treatment of red amorphous phosphorus resulted in the formation of the black, orthorhombic phase of phosphorus. Fig. 2b shows the Raman spectra of ball milled phosphoruscarbon composites C-1 and C-2. The phosphorus bands cannot be seen in either sample. The carbon component shows two strong bands at about 1350 and $1600 \mathrm{~cm}^{-1}$, typically referred to in the literature as $\mathrm{D}$ and $\mathrm{G}$ bands of graphite, ${ }^{24}$ in both nanocomposites. The $\mathrm{D}$ and $\mathrm{G}$ bands in the composite $\mathrm{C}-2$ have much larger FWHMs comparing with those in the composite C1 , which reveals a more disordered in-plane structure. ${ }^{25,26}$ For example, the FWHM of the D band is $120 \mathrm{~cm}^{-1}$ for the composite C-2, comparing with only $70 \mathrm{~cm}^{-1}$ in the composite $\mathrm{C}-1$, indicating a much higher degree of in-plane distortion and disordering in the graphitic structure in the composite C-2.

The ${ }^{31} \mathrm{P}$ NMR spectra of red amorphous phosphorus, black phosphorus and phosphorus-carbon composites C-1 and C-2 are shown in Fig. 3. The spectra of red phosphorus (Fig. 3a) shows very broad signals around $\delta=-80,+60$ and $+150 \mathrm{ppm}$, indicating a highly inhomogeneous, amorphous environment for the ${ }^{31} \mathrm{P}$ nuclei in this material. The measured chemical shifts match the shifts of red and violet phosphorus samples observed by Bytchkov et al. $^{27}$ The black $\mathrm{P}$ (Fig. $3 \mathrm{~b}$ ) spectrum shows a strong signal at $\delta=22 \mathrm{ppm}$ with a weaker, broad shoulder at about 10-0 ppm. The observed chemical shift is in agreement with a black phosphorus spectrum acquired by Lange et al. ${ }^{28}$ whereas the smaller line width indicates a more homogeneous environment for the ${ }^{31} \mathrm{P}$ nuclei in this material with a higher 

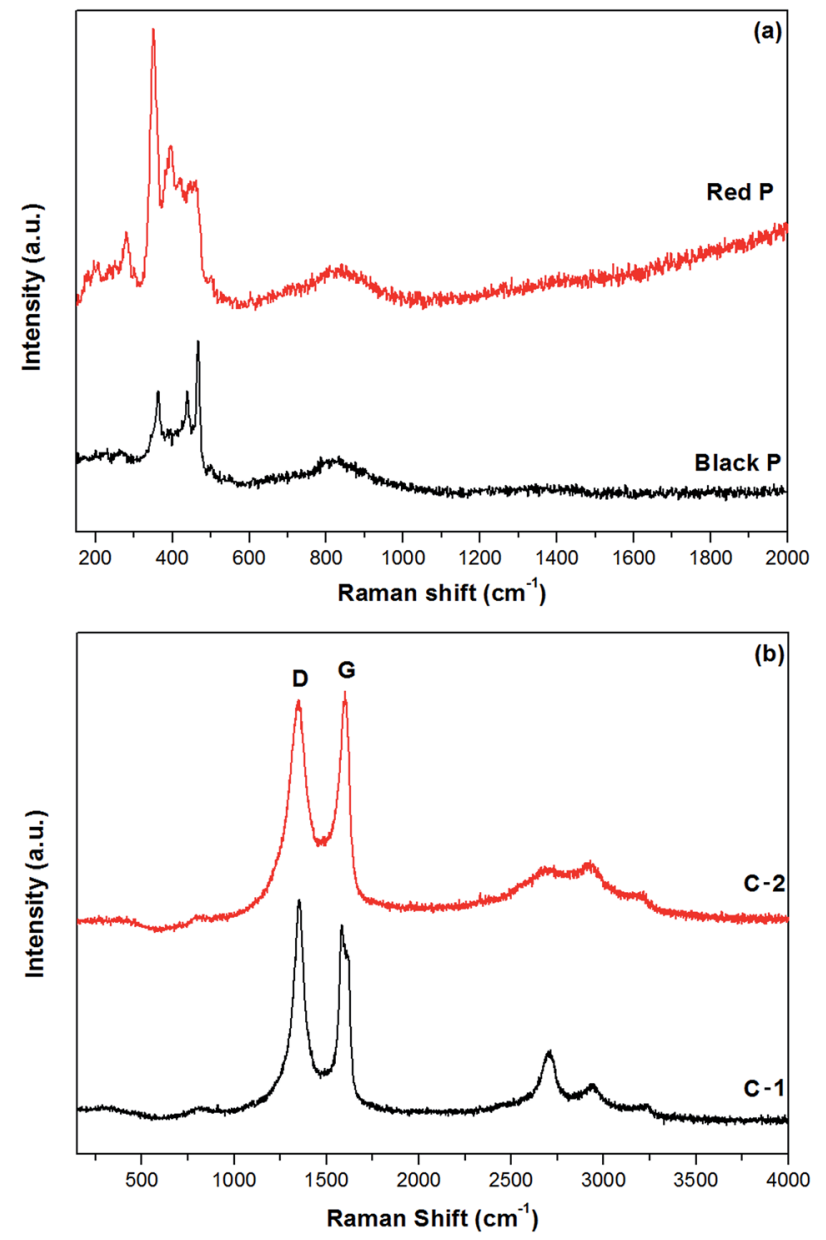

Fig. 2 Raman spectra of samples of red and black phosphorus (a) and phosphorus-carbon composites C-1 and C-2 (b).

crystallinity when compared to the red phosphorus sample. A similar trend can be observed for the respective phosphoruscarbon nanocomposites, but with the main signal in the composite C-2 (Fig. 3d) showing a very broad signal shifted to around $\delta=10 \mathrm{ppm}$, very similar to the signal of composite C-1 (Fig. 3c). The even broader line width of C-2 is also indicating a very inhomogeneous, amorphous environment, but with the chemical shift and thus an electronic environment and structure closer to black P.

The results of TEM analysis of phosphorus and composite samples are shown in Fig. 4. The electron diffraction pattern of the commercial red phosphorus (Fig. 4a; a bright-field image is also shown as an inset) displays only diffuse rings, consistent with the amorphous nature of this sample. In contrast, the diffraction pattern of black phosphorus (Fig. 4b) displays a set of polycrystalline rings that can be indexed in accordance with the expected orthorhombic phase. In particular, rings corresponding to the (012), (004), (016) and (121) lattice planes can be distinguished.

Energy-filtered TEM was employed to understand the differences in the structure of the composites C-1 and C-2. Fig. $4 \mathrm{c}$ and $\mathrm{f}$ show elastic images of the two composites, their

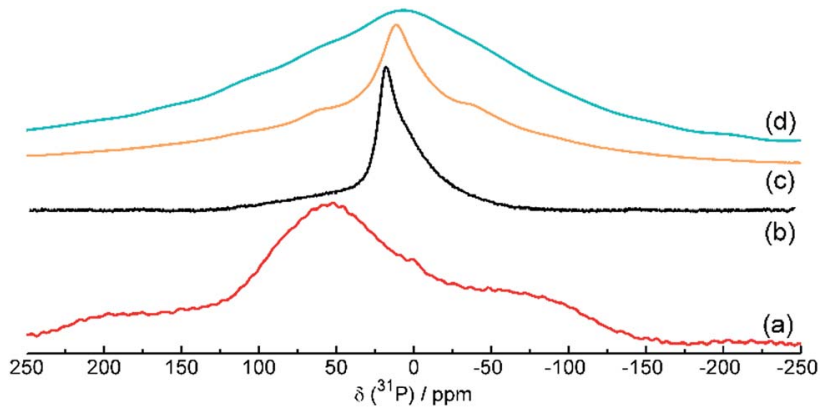

Fig. $3{ }^{31} \mathrm{P}$ solid-state NMR spectra of red amorphous phosphorus (a), mechanochemically produced black phosphorus (b), phosphoruscarbon composite C-1 (c) and phosphorus-carbon composite C-2 (d).

carbon elemental maps are depicted in Fig. $4 \mathrm{~d}$ and g, and the phosphorus elemental maps are depicted in Fig. $4 \mathrm{e}$ and $\mathrm{h}$. There is a clear difference between the carbon and phosphorus maps of the composite C-1. These maps are not identical, and, furthermore, nanoparticles can be observed in the phosphorus elemental map of C-1 (some of them highlighted with white arrows in Fig. 4e). After a careful inspection of the elastic image (Fig. 4c), the same nanoparticles can be seen as the areas with darker contrast (highlighted with arrows). Taking into account the nanocrystalline peaks of orthorhombic phosphorus in the XRD pattern of C-1 (Fig. 1c), the TEM data are consistent with the presence of crystalline phosphorus nanoparticles in the carbon host in the composite C-1.

In contrast, the elastic image, carbon and phosphorus maps of the composite C-2 (Fig. 4f-h) are essentially identical. No clear nanoparticles are visible in Fig. $4 \mathrm{~h}$, and the phosphorus and carbon maps repeat each other. It can be concluded that the phosphorus and carbon are distributed much more homogeneously in the composite C-2. As the spacial resolution of the EFTEM technique is 1-2 nm, our interpretation of the acquired data suggests the presence of very small nanoparticles or nanoclusters of phosphorus with a typical size of $1 \mathrm{~nm}$ or less, homogeneously distributed within the carbon component of the composite C-2. In accordance with the XRD and NMR data, these nanoclusters are significantly disordered but may retain the local environment of the black orthorhombic phosphorus.

It is worthwhile to compare our characterisation results with those of other groups for phosphorus-carbon nanocomposites prepared by ball milling. ${ }^{5,8,13,18,19}$ The differences and similarities in the composition and structure of the composites may shed light on the differences and similarities in their electrochemical performance. As we pointed out, the phosphorus in the composites $\mathrm{C}-1$ and $\mathrm{C}-2$ described here is in the form of black, orthorhombic phase (either crystalline or somewhat disordered). This is likely to originate from the "history" of preparation because the powder of black phosphorus was initially produced and subsequently used for preparing the composites. It is likely that the phosphorus component in the composites inherits at least the local environments of the black, orthorhombic parent phase. It is important to note that the composites prepared by Qian et al. ${ }^{8,19}$ for both lithium-ion and 

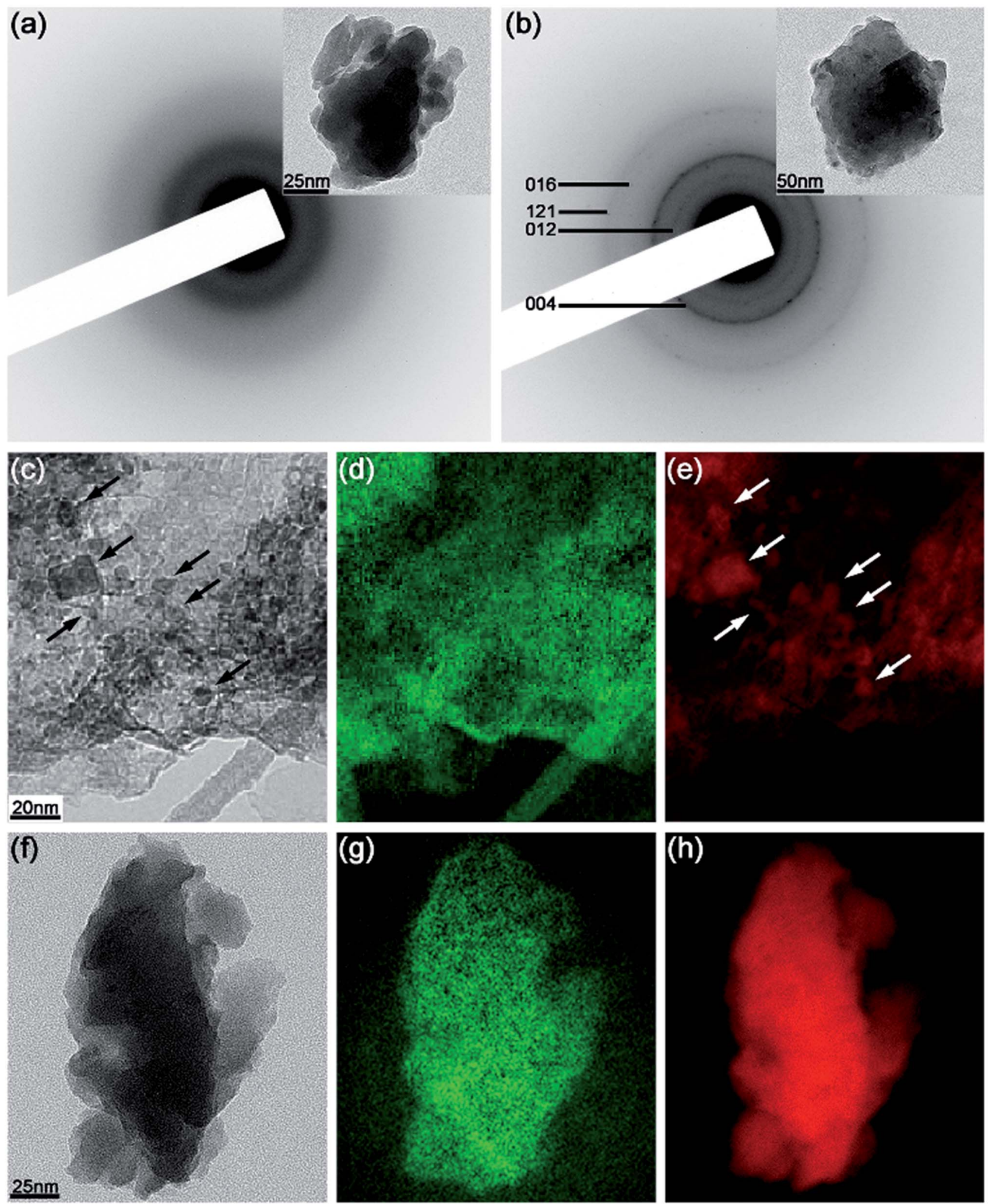

Fig. 4 TEM analysis of phosphorus and phosphorus-carbon samples. (a and b) Selected area electron diffraction patterns of the red and black phases of phosphorus (bright-field images are shown as insets); (c-e) an elastic image, carbon and phosphorus energy-filtered elemental maps of the composite $\mathrm{C}-1 ;(f-h)$ an elastic image, carbon and phosphorus energy-filtered elemental maps of the composite $\mathrm{C}-2$ (colour scheme: green - carbon, red - phosphorus). 
sodium-ion anodes were also produced via the formation of an intermediate black phase of phosphorus in the composite (refer to the manuscripts and related Supporting Information). Although these authors have described their composites as "amorphous phosphorus/carbon nanocomposites", it seems that at least some of their materials may be still in the form of black phosphorus (which is evident from the presence of crystalline spots in electron diffraction patterns (ref. 19 and Fig. 1b)) and weak Raman bands at 466 and $437 \mathrm{~cm}^{-1}$ (ref. 8 and Fig. 1b). Due to the similarity of preparation method and the presence of the intermediate black phase, the structure of their material may be close to the structure of our composite C-2 although differences in Raman signatures exist (next paragraph). We believe that our another composite, $\mathrm{C}-1$, is, on the other hand, structurally similar to that produced by Park and Sohn, ${ }^{5}$ who ball milled carbon black and black phosphorus directly to prepare a composite.

As explained, the Raman spectra do not reveal the presence of the phosphorus bands for the composites C-1 and C-2. Similar lack of Raman signatures has been observed by Kim et al. ${ }^{18}$ Qian et al.,${ }^{8,19}$ in contrast, have observed weak bands at 437 and $466 \mathrm{~cm}^{-1}$, typical for black phosphorus in the Raman spectra of their composites. Sun et al. ${ }^{13}$ have also detected the presence of Raman bands of black phosphorus in their composite. The presence or lack of phosphorus Raman signals may reflect some differences in the structure of these composites. A Raman feature at about $600-750 \mathrm{~cm}^{-1}$ was assigned to $\mathrm{P}-\mathrm{C}$ bonds by Sun $e t$ al. ${ }^{13}$ This Raman signature as well as a high-resolution TEM image of a phosphorus-carbon boundary and some XPS data have been used by these researchers as evidence for the presence of phosphoruscarbon bonds, which, according to the manuscript, lead to an improved performance of the material in the lithium-ion battery. Although the formation of phosphorus-carbon bonds or compounds is indeed possible in nanocomposites and is an important consideration, further research is warranted in this area to confirm conclusions about the formation of phosphorus-carbon bonding or any phosphorus-carbon phases.

Information on the distribution of phosphorus in the composites is currently limited. Efforts in systematic mapping of phases by transmission electron microscopy techniques are required to understand this further. Kim et al. ${ }^{18}$ have presented energy-dispersive X-ray maps of phosphorus and carbon but the resolution of the scans was somewhat limited to pinpoint the differences in the distribution of elements. Another possible problem with the energy-dispersive X-rays maps is a low sensitivity of this method to light elements. Mapping methods based on the energy loss of electrons could be more suitable due to their higher sensitivity to C and P. In this work, we have used energy-filtered elemental mapping and were able to demonstrate that the distributions of the phosphorus component in the composite C- 1 and C- 2 are quite different. Further efforts in characterising the composites may be focused on the applications of electron energy loss spectrum imaging in the scanning TEM mode.

\section{Electrochemical performance in the $2.0-0.01 \mathrm{~V}$ potential window vs. $\mathrm{Li} / \mathrm{Li}^{+}$and $\mathrm{Na} / \mathrm{Na}^{+}$}

The electrochemical performance of the phosphorus-carbon nanocomposites in lithium half-cells is shown in Fig. 5. The initial discharge capacity (1930 $\mathrm{mA} \mathrm{h} \mathrm{g}^{-1}$ ) and Coulombic efficiency $(86.9 \%)$ of the composite $\mathrm{C}-1$ are quite attractive, although the capacity declines monotonously in the following cycles (Fig. 5a). The discharge capacities measured in the second, seventh and $50^{\text {th }}$ cycles are 1654, 1446 and $349 \mathrm{~mA} \mathrm{~h}$ $\mathrm{g}^{-1}$, respectively. The electrochemical stability of the composite C-2 is inferior to that of the composite C-1 (Fig. 5b). Specifically, the electrode of C-2 demonstrates a steep decline in capacity, with discharge capacities of 1995, 1642, 748 and $49 \mathrm{~mA} \mathrm{~h} \mathrm{~g}^{-1}$ measured in the first, second, seventh and 50th cycles, respectively. An interesting observation in the composite C-2 was a sudden drop of capacity in the tenth cycle, in which the charge capacity was dramatically lower than the discharge capacity. The initial Coulombic efficiency of the composite C-2 in the first cycle was similar to that of C-1 (85.5\%). Overall, both composites demonstrate declining capacities upon progressive cycling, while the decline appears to be gradual for the composite C-1 and quite abrupt for the composite $\mathrm{C}-2$.

The charge-discharge curves of the composites C- 1 and C-2 are shown in Fig. 5c and d. The first discharge curves of the composites are different from the subsequent ones and have an irreversible hump at about $1.3-0.95$ and $1.2-0.85 \mathrm{~V} v s . \mathrm{Li}^{2} \mathrm{Li}^{+}$, for the composites C-1 and C-2, respectively. A similar irreversible hump at around the same potentials was observed for the phosphorus-carbon composites by Park and $\mathrm{Sohn}^{5}$ and Qian et al. ${ }^{8}$ Similarly to the previous reports, composites C- 1 and C-2 uptake most of lithium within potential windows $0.95-0.45 \mathrm{~V}$ and $0.85-0.4 \mathrm{~V} v s . \mathrm{Li}^{2} \mathrm{Li}^{+}$, respectively. In the course of the charge of the half-cells the composites C-1 and C-2 release most of lithium within the potential windows of $0.9-1.25 \mathrm{~V}$ and $0.8-1.2$ $\mathrm{V}$ vs. $\mathrm{Li} / \mathrm{Li}^{+}$. Polarisation of the charge-discharge curves increases rapidly upon cycling for both composites, and this phenomenon is more pronounced for the composite C-2.

Before discussing the electrochemical results in lithium cells and comparing them with literature, it is important to mention that different authors calculate the reported capacity differently, and this complicates the process of comparing data. In particular, some authors neglect the capacity of the carbon component completely (all measured capacity was attributed to the phosphorus component), ${ }^{4,8,10}$ some estimated the capacity of the phosphorus component ${ }^{11}$ and some measured the capacity per total mass of the composite (this work and ref. 11 and 13). Another important consideration is the use of different active material loadings in the electrodes by different authors, and the electrodes with thinner coating of active materials might be, in general, showing better electrochemical performances. In some case, the active material loadings have not been reported. The available experimental results for the phosphorus-carbon composites are summarised in Table 1.

The results reported in the literature for lithium cells can be broadly classified into two groups. One group of results suggests a gradual and significant deterioration in the performance in 

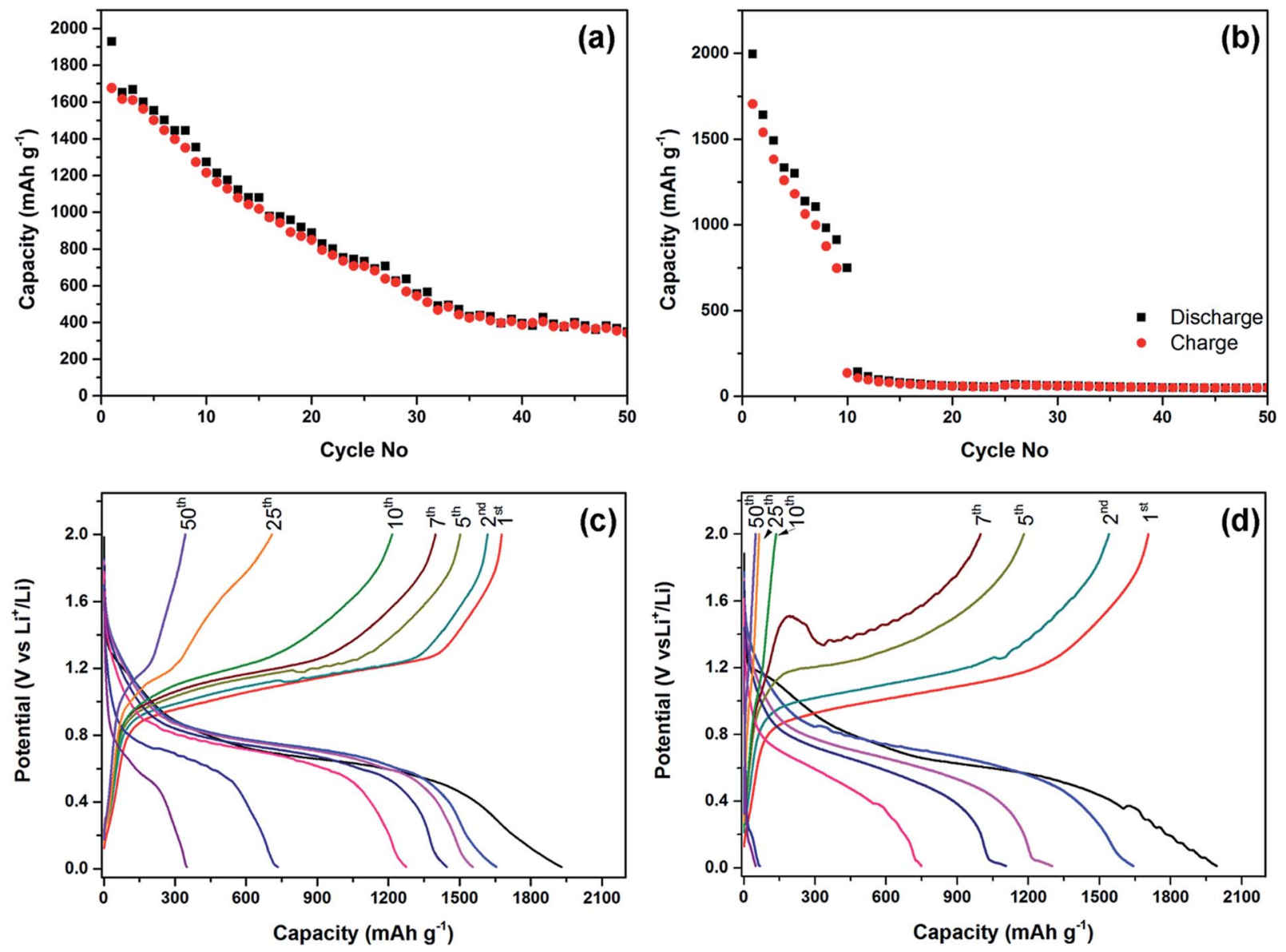

Fig. 5 Electrochemical performance of the phosphorus-carbon composites in lithium half-cells within the potential window of 2.0-0.01 $\mathrm{V}$ vs. $\mathrm{Li} / \mathrm{Li}^{+}$at a current rate of $100 \mathrm{~mA} \mathrm{~g}^{-1}$ : (a and b) cyclic performance of the composites C-1 and C-2, respectively; (c and d) galvanostatic chargedischarge profiles of the composites $\mathrm{C}-1$ and $\mathrm{C}-2$.

phosphorus-carbon composites. For example, activated amorphous phosphorus-carbon composite with the component ratio of $1: 1$ synthesised by Marino et al. displayed capacity retention of $64.9 \%$ at the end of $20^{\text {th }}$ cycle. ${ }^{4}$ The capacity of black phosphorus-acetylene black electrode in a solid-state cell declined from 1746 to about $500 \mathrm{~mA} \mathrm{~h} \mathrm{~g}{ }^{-1}$ after 150 cycles. $^{10}$ The capacity of black phosphorus-carbon composite prepared by ball milling by Park and Sohn ${ }^{5}$ dropped from 1814 to about $200 \mathrm{~mA}$ $\mathrm{h} \mathrm{g}^{-1}$ after 30 cycles within a potential window of $2.0-0.01 \mathrm{~V} v s$. $\mathrm{Li} / \mathrm{Li}^{+}$. The latter material, as we expect, is structurally similar to our composite C-1. In the case of our C-1 composite, the cyclic behaviour was similar at a qualitative level to that for the composite in ref. 5 but a better capacity retention was observed (349 $\mathrm{mA} \mathrm{h} \mathrm{g}^{-1}$ after 50 cycles). This can be correlated with a lighter active material loading $\left(1 \mathrm{mg} \mathrm{cm}{ }^{-2}\right.$ instead of $2.5 \mathrm{mg}$ $\mathrm{cm}^{-2}$ ) and a more suitable binder (sodium carboxymethyl cellulose instead of polyvinylidene fluoride). Taking these difference into account, the behaviour of our composite C-1 was consistent with the behaviour of the black P-carbon composite reported by Park and Sohn. ${ }^{5}$

Three other reports have claimed only moderate declines in capacity and attractive cyclic stabilities over many cycles. Nanostructured phosphorus-porous carbon composite prepared by Wang et al. ${ }^{11}$ has demonstrated capacity retention of $87 \%$ at the end of $55^{\text {th }}$ cycle. However, the phosphorus content in the composite was around $32.6 \%$, very low, which might be a reason behind the excellent cycling stability of the electrodes in this work. ${ }^{11}$ Due to the high content of the carbon component, the capacity per total weight of the composite was moderate, only at a level of $740-840 \mathrm{~mA} \mathrm{~h} \mathrm{~g}{ }^{-1}$. Sun et al. ${ }^{13}$ have reported $80 \%$ retention of capacity in the ball milled black phosphorus-graphite composite, while Qian et al. ${ }^{8}$ have reported $90 \%$ retention of capacity in their amorphous phosphoruscarbon composite (both after 100 cycles). The last two reports demonstrate significantly better cyclic performance of the phosphorus-carbon nanocomposites prepared by ball milling. It is not clear at this stage what leads to such an improvement. Sun et al. have suggested that the formation $\mathrm{P}-\mathrm{C}$ bonds in their composite played an important role in the improvement of cyclic stability, and the cyclic performance was also a function of the carbon material used as a precursor to create a composite. ${ }^{13}$ Qian et al. have indicated that the milling time was an important parameter for the performance of their composites. The composites milled for either 6 and $12 \mathrm{~h}$ have shown deteriorating cyclic performance with increasing polarisation in the charge-discharge curves while the composite milled for $24 \mathrm{~h}$ 
Table 1 Electrochemical performance of phosphorus-carbon composites in lithium half-cells

\begin{tabular}{|c|c|c|c|c|}
\hline Sample & $\begin{array}{l}\text { Active material loading, } \\
\mathrm{mg} \mathrm{cm}^{-2}\end{array}$ & $\begin{array}{l}\text { Initial discharge/charge } \\
\text { capacity, } \mathrm{mA} \mathrm{h} \mathrm{g}^{-1}\end{array}$ & Cyclic performance & Reference \\
\hline $\mathrm{C}-1$ & $0.92-1.05$ & $1930 / 1677^{a}$ & $\begin{array}{l}\text { Declining gradually. } \\
\text { Capacity of } 349 \mathrm{~mA} \mathrm{~h} \mathrm{~g}{ }^{-1} \text { in } \\
\text { the } 50 \text { th cycles. }\end{array}$ & This work \\
\hline $\mathrm{C}-2$ & $0.92-1.05$ & $1995 / 1706^{a}$ & $\begin{array}{l}\text { Declining more abruptly. } \\
\text { Capacity of only } 49 \mathrm{~mA} \mathrm{~h}^{-1} \\
\text { in the 50th cycle. }\end{array}$ & This work \\
\hline $\begin{array}{l}\text { Amorphous phosphorus- } \\
\text { carbon composite }\end{array}$ & $\sim 3$ & $2651 / 2355^{b}$ & $\begin{array}{l}\text { Minor decline. } 90 \% \text { of } \\
\text { capacity is reported to } \\
\text { remain after } 100 \text { cycles }\end{array}$ & 8 \\
\hline $\begin{array}{l}\text { Activated phosphorus- } \\
\text { carbon composite }\end{array}$ & Not reported & $3289 / 1385^{b}$ & $\begin{array}{l}\text { Declining. } 900 \mathrm{~mA} \mathrm{~h} \mathrm{~g}^{-1} \\
\text { capacity after } 20 \text { cycles }\end{array}$ & 4 \\
\hline $\begin{array}{l}\text { Black phosphorus-carbon } \\
\text { composite }\end{array}$ & 2.5 & $2010 / 1814^{a}$ & $\begin{array}{l}\text { Declining. Capacity of about } \\
200 \mathrm{~mA} \mathrm{~h} \mathrm{~g}^{-1} \text { after } 30 \text { cycles }\end{array}$ & 5 \\
\hline $\begin{array}{l}\text { Nanostructured red } \\
\text { phosphorus-carbon } \\
\text { composite }\end{array}$ & Not reported & $1200 / 840^{a}$ & $\begin{array}{l}\text { Relatively stable capacity. } \\
\text { Minor decline. } 745 \mathrm{~mA} \mathrm{~h} \mathrm{~g}{ }^{-1} \\
\text { after } 50 \text { cycles }\end{array}$ & 11 \\
\hline $\begin{array}{l}\text { Black phosphorus-graphite } \\
\text { composite }\end{array}$ & $2.0-2.8$ & $2786 / 2382^{a}$ & $\begin{array}{l}\text { Minor decline. } 80 \% \text { of } \\
\text { capacity is reported to } \\
\text { remain after } 100 \text { cycles }\end{array}$ & 13 \\
\hline
\end{tabular}

has demonstrated dramatically improved cyclic performance. The preparation methods used in this work and in ref. 5, 8 and 13 are quite similar. Further research will be required to understand the origin of significant differences observed in the electrochemical performances.

The electrochemical performance of the phosphorus-carbon nanocomposites C-1 and C-2 in sodium half-cells is shown in Fig. 6. The initial discharge capacity of the composite C-1 was $1530 \mathrm{~mA} \mathrm{~h} \mathrm{~g}^{-1}$ and its measured Coulombic efficiency was 86.4\%. After a minor decline in capacity in the first 15 cycles to $1193.9 \mathrm{~mA} \mathrm{~h} \mathrm{~g}^{-1}$, the capacity drop accelerates afterwards and a capacity of $187 \mathrm{~mA} \mathrm{~h} \mathrm{~g}^{-1}$ can be measured in the $50^{\text {th }}$ cycle (Fig. 6a). The cyclic performance of the composite C-2 is again inferior to that of $\mathrm{C}-1$. The electrode demonstrates a steeper decline in capacity (Fig. 6b), and the discharge capacities measured in the first, second, tenth and $50^{\text {th }}$ cycles are 1427 , 1321, 991 and $119 \mathrm{~mA} \mathrm{~h} \mathrm{~g}{ }^{-1}$. The initial Coulombic efficiency was $89.9 \%$. The high Coulombic efficiency emphasises that, in principle, the studied phosphorus-carbon composites may be highly reversible sodium anodes if the deficiencies in their cyclic performance are addressed.
The charge-discharge curves of the composites C- 1 and C-2 are shown in Fig. $6 \mathrm{c}$ and d. The first discharge curves of the composites are different from the subsequent ones and have an irreversible hump at about 1.1-0.65 and 0.95-0.65 $\mathrm{V} v s . \mathrm{Na} / \mathrm{Na}^{+}$, for the composites $\mathrm{C}-1$ and $\mathrm{C}-2$, respectively. The second and subsequent discharge curves of the composites were different to the first discharge. There are three voltage regions in the corresponding discharge cycle (i) a sharp slope down to $0.5 \mathrm{~V} v s$. $\mathrm{Na} / \mathrm{Na}^{+}$, (ii) a sloping plateau (or, possibly, a series of plateaus) in the range of $0.5-0.15 \mathrm{~V} v s$. $\left(\mathrm{Na} / \mathrm{Na}^{+}\right)$, and (iii) a minor plateau at around $0.07-0.11 \mathrm{~V} v s$. $\mathrm{Na} / \mathrm{Na}^{+}$, which disappears after a few cycles. Most of sodium release takes place between $0.4-0.8 \mathrm{~V} v \mathrm{~s}$. $\mathrm{Na} / \mathrm{Na}^{+}$. The observed behaviour of the charge-discharge curves is similar to that observed elsewhere. ${ }^{\mathbf{1 8 , 1 9}}$ After comparing the exact behaviour of the composites $\mathrm{C}-1$ and $\mathrm{C}-2$, we can also note the appearance of a small plateau, which disappears after a few cycles, at about $0.6 \mathrm{~V} v s$. $\mathrm{Na} / \mathrm{Na}^{+}$during charging of the half cell with the composite $\mathrm{C}-1$.

Literature data on the performance on phosphorus-carbon composite electrodes are presented in Table 2. Promising performance of phosphorus-carbon nanocomposites has been previously highlighted by Kim et al. ${ }^{18}$ and Qian et al. ${ }^{19}$ The 

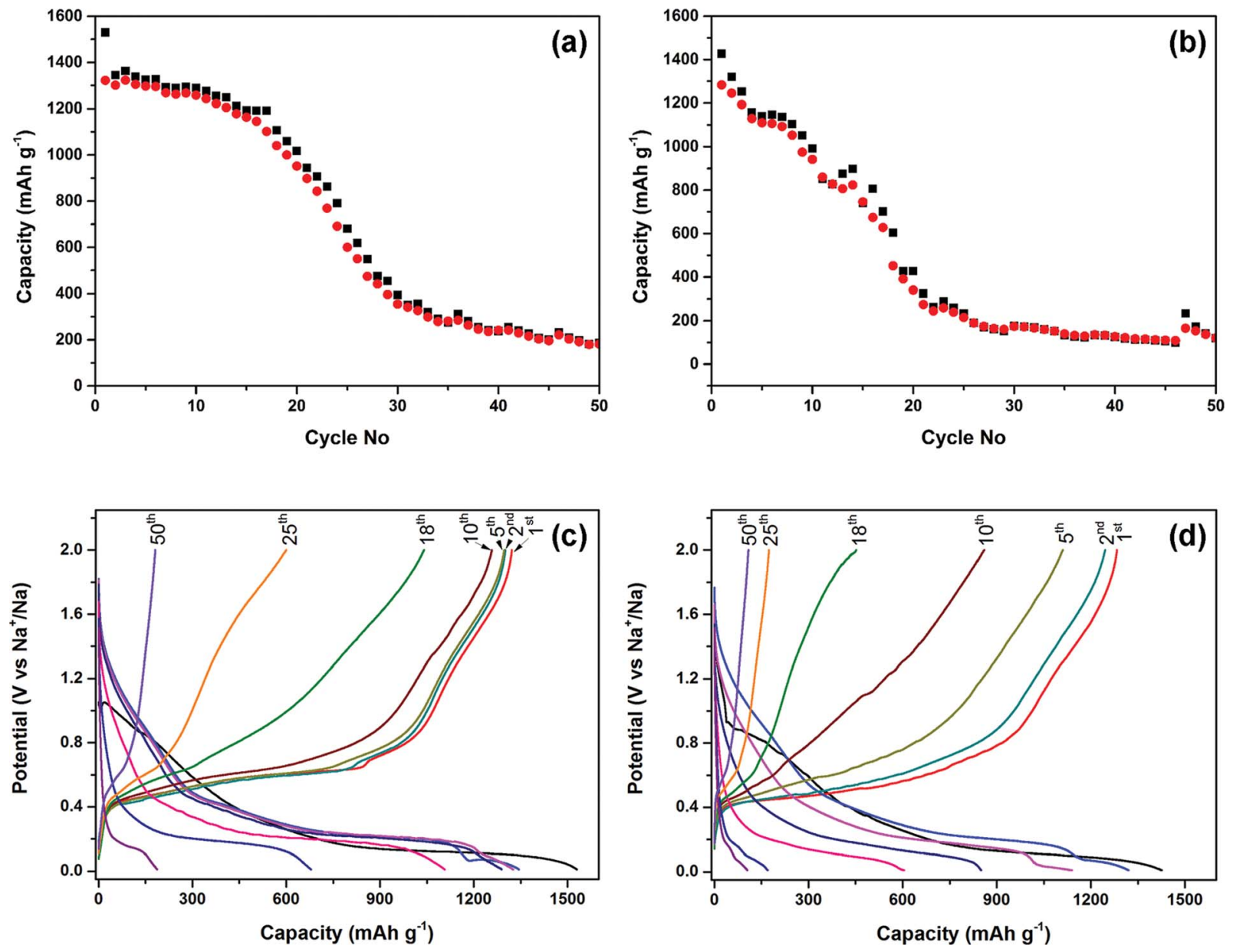

Fig. 6 Electrochemical performance of the phosphorus-carbon composites in sodium half-cells within the potential window of $2.0-0.01 \mathrm{~V}$ vs. $\mathrm{Na} / \mathrm{Na}^{+}$at a current rate of $100 \mathrm{~mA} \mathrm{~g}^{-1}$ : ( $a$ and b) cyclic performance of the composites $\mathrm{C}-1$ and $\mathrm{C}-2$, respectively; (c and d) galvanostatic charge-discharge profiles of the composites C-1 and C-2.

former report demonstrates the electrochemical performance at a slightly elevated temperature of $30{ }^{\circ} \mathrm{C}$ and relatively stable cyclability (with only $7 \%$ of capacity drop) is shown for 30 cycles. It is not clear if the performance remains stable after 30 cycles in this report. In the latter report, ${ }^{19}$ the cyclic performance has been evaluated for 60 cycles and, although stable for the first 35 cycles, the capacity has been found to decline dramatically between $35^{\text {th }}$ and $60^{\text {th }}$ cycles. These authors have also reported that the addition of $10 \%$ of fluoroethylene carbonate (FEC) to the electrolyte is capable of improving the cyclic performance, and electrochemical performance with slow continuous decline in capacity for 140 cycles has been demonstrated. Similar observation about the role of FEC has been reported by Yabuuchi et al., ${ }^{21}$ suggesting that the addition of FEC improves electrode reversibility. Declining cyclic performance has been reported by Li et al. ${ }^{20}$ In their work, the reversible capacity has been shown to decline $23.4 \%$ after only 10 cycles but the composite was prepared by simple grinding of red phosphorus and carbon nanotubes by hand. Our results indicate that the composite C-1 is capable of sustaining high capacity for the first 15 cycles, with accelerating decline afterwards (the electrolyte with $2 \%$ FEC in it was used). It seems to be generally consistent with other reports, where high capacity could be sustained for a number of cycles and accelerated degradation was observed afterwards.

While discussing the performance of phosphorus-carbon composites in sodium half-cells, it is important to point out that various researchers use different electrolytes (salts and solvents) for testing as there is still no commonly accepted electrolyte for this new type of batteries. We used $1 \mathrm{M} \mathrm{NaClO}_{4}$ in propylene carbonate (PC) with $2 \%$ FEC in this work. Similar electrolyte was used by Yabuuchi et al. ${ }^{21} \mathrm{~A}$ combination of ethylene carbonate (EC) and diethyl carbonate (DEC) as a solvent with either $\mathrm{NaPF}_{6}$ of $\mathrm{NaClO}_{4}$ salt and with or without FEC was used by Li et al., ${ }^{20}$ Kim et al. ${ }^{18}$ and Qian et al. ${ }^{19}$

Another important variable that affects the cyclic performance in both lithium and sodium cells is obviously the choice of a binder used in the electrodes. Polyvinylidene fluoride (PVDF), ${ }^{5,13,21}$ (sodium) carboxymethyl cellulose (CMC), ${ }^{4,8,9,19}$ polyacrylic acid (PAA), ${ }^{18}$ polyacrylonitrile ${ }^{11}$ and sodium polyacrylate (PANa) ${ }^{21}$ were used in phosphorus-carbon composite electrodes in lithium and sodium cells. CMC was used as a binder in the present work. Future systematic study is required to understand the most suitable binder for this type of electrode 
Table 2 Electrochemical performance of phosphorus-carbon composites in sodium half-cells

\begin{tabular}{|c|c|c|c|c|}
\hline $\mathrm{C}-1$ & $0.92-1.05$ & $1530 / 1322^{a}$ & $\begin{array}{l}\text { Slowly declining in the first } \\
15 \text { cycles and faster } \\
\text { afterward. Capacity of } 187 \\
\mathrm{~mA} \mathrm{~h}^{-1} \text { in the } 50 \text { th cycle }\end{array}$ & This work \\
\hline
\end{tabular}

C-2

Amorphous red

phosphorus-carbon

Amorphous carbon-

phosphorus composite

Red phosphorus-carbon

nanotube composite

Red phosphorus-acetylene

black mixture composite

$0.92-1.05$

$1.4-2.1$

3

Not reported

$0.4-0.46$

${ }^{a}$ Capacity is calculated per total weight of the phosphorus-carbon composite. ${ }^{b}$ All capacity is assigned to the phosphorus component, the capacity of carbon components is neglected as minor contribution.
$2210 / 1675^{b}$

$1427 / 1283^{a}$

$2223 / 1890^{b}$

$2015 / 1764^{b}$

Reversible capacity of about $2150^{b}$
Declining. Capacity of 119 $\mathrm{mA} \mathrm{h} \mathrm{g}^{-1}$ in the 50th cycles

Minor decline. $93 \%$ of capacity is retained after 30 cycles

Stable cyclic performance for 35 cycles with accelerating decline afterwards. Monotonous slow decline in the electrolyte with added FEC

Declining. $76.6 \%$ Of capacity is retained after 10 cycles

Declining. Capacity of about 800 remains after 10 cycles
This work

19

20

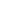

material, the available information is not adequate to choose the optimal binder reliably. The general view is that the conventional PVDF is a poor choice of a binder for phosphorusbased electrodes and gives inferior performance. For example, an electrode with PANa binder has been shown to provide a much better performance than that of the electrode with PVDF binder in sodium cells in ref. 21. Intriguingly, one of the best electrochemical performances in lithium cells ${ }^{13}$ was claimed in a study using PVDF as a binder.

\section{Electrochemical performance in the restricted potential windows $v s . \mathrm{Li} / \mathrm{Li}^{+}$and $\mathrm{Na} / \mathrm{Na}^{+}$}

It is commonly accepted that the deteriorating cyclic performance observed within the potential window of $2.0-0.01 \mathrm{~V} v s$. $\mathrm{Li} / \mathrm{Li}^{+}$or $\mathrm{Na} / \mathrm{Na}^{+}$(Fig. 5 and 6) is likely to originate from significant volume changes during the lithium and sodium alloying and de-alloying processes in the phosphorus component. ${ }^{5,8,19,21}$ For example, volume change of almost $300 \%$ (ref. 21) is expected in phosphorus in the course of its reaction with sodium. The dramatic volume change may impact the integrity of the electrodes during the repetitive cycling. Park and Sohn ${ }^{5}$ have previously pointed out that a stable cyclic behaviour in electrodes based on black phosphorus can be achieved in a lithium half-cell if the operating potential window is restricted (to $2.0-0.78 \mathrm{~V} v s$. $\mathrm{Li}^{-} \mathrm{Li}^{+}$in their case). If the operating potential is restricted to $2.0-0.78 \mathrm{~V} v s$. $\mathrm{Li} / \mathrm{Li}^{+}$, black phosphorus transforms reversibly into the LiP phase, and the associated volume change is significantly reduced, leading to a stable capacity of the electrode. ${ }^{5}$ We have attempted to re-check these finding for the lithium cells and evaluate if similar stabilisation of capacity may happen in the case of sodium half-cells.

Fig. 7a shows the cycling stability of the composite C-1 in the potential window of $2.0-0.67 \mathrm{~V} v$ s. $\mathrm{Li}^{-} \mathrm{Li}^{+}$in a lithium half-cell. Relatively stable capacity of slightly above $700 \mathrm{~mA} \mathrm{~h} \mathrm{~g}{ }^{-1}$ can be observed. Some variations in the capacity visible in the graphs in Fig. 7 are due to the temperature variations in our laboratory over the course of an Australian winter. It can be concluded from the measured data that, in line with earlier findings by Park and Sohn ${ }^{5}$ stable capacity can be achieved in black phosphorus-carbon composites in a restricted potential window in lithium half-cells. The measured capacity in this study was somewhat higher than that in the previous work $\left(\sim 600 \mathrm{~mA} \mathrm{~h} \mathrm{~g}^{-1}\right)^{5}$ because of a lower cut-off potential used in the present work.

Our measurements indicate (Fig. $7 \mathrm{~b}$ and $\mathrm{c}$ ), that similar stable cyclic behaviour can be achieved in sodium half-cells if the potential window is restricted to $2.0-0.33 \mathrm{~V}$ vs. Na/Na ${ }^{+}$. Indeed, both composite C-1 (Fig. 7b) and composite C-2 (Fig. 7c) are able to demonstrate rather stable capacity of about $400 \mathrm{~mA} \mathrm{~h}$ $\mathrm{g}^{-1}$. The cut-off potential used for sodium cells is lower than that for lithium half-cells as the electrochemical reactivity of phosphorus-based electrodes with sodium happens at lower potentials. To sum up, phosphorus-carbon electrodes were able to deliver stable capacities (approximately 700 and $400 \mathrm{~mA} \mathrm{~h}$ 

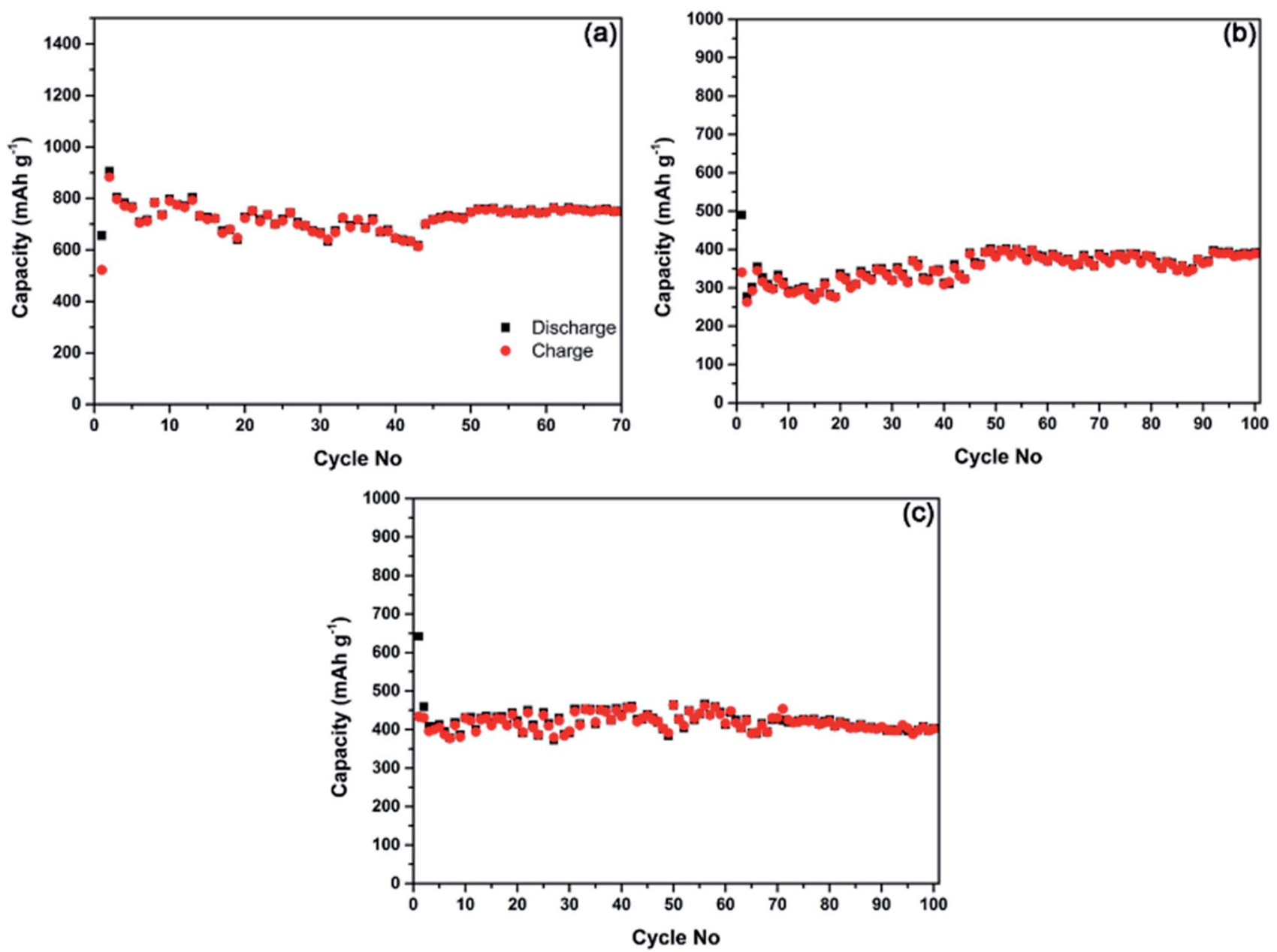

Fig. 7 Electrochemical performance of the electrodes cycled within restricted potential windows at $100 \mathrm{~mA} \mathrm{~g}^{-1}$; (a) cyclic performance of the composite $\mathrm{C}-1$ between 2.0 and $0.67 \mathrm{~V}$ vs. Li/Li+; (b and c) cyclic performance of the phosphorus-carbon composites C-1 and C-2 between 2.0 and $0.33 \vee v s$. $\mathrm{Na} / \mathrm{Na}^{+}$.

$\mathrm{g}^{-1}$ ) in lithium and sodium half-cells in restricted potential windows.

\section{Insights into the charge storage and failure mechanisms}

In order to investigate the charge storage mechanisms, ex situ XRD measurements were conducted on the C- 1 composite electrodes extracted from lithium or sodium half-cells after their first discharge to $0.01 \mathrm{~V}$ vs. $\mathrm{Li} / \mathrm{Li}^{+}$or $\mathrm{Na} / \mathrm{Na}^{+}$. Fig. 8a shows that $\mathrm{Li}_{3} \mathrm{P}$ phase forms after the first discharge of the $\mathrm{C}-1$ electrode in a lithium-cell. There are no peaks of black $\mathrm{P}$ observed in Fig. 8a, suggesting that almost all the phosphorus in the electrode reacts with lithium to yield $\mathrm{Li}_{3} \mathrm{P}$. Such an electrochemical reaction agrees well with previous reports ${ }^{5,7,10}$ on the use of black phosphorus in Li-ion systems, and the charge is suggested to happen predominantly via a reversible phase change of $\mathrm{P}$ to $\mathrm{Li}_{3} \mathrm{P}$ and back. In contrast, the XRD pattern of the C-1 electrode after the discharge in a sodium half-cell indicates that two phases are present in the electrode (Fig. 8b). One phase corresponds to $\mathrm{Na}_{3} \mathrm{P}$ and the second phase is unidentified. The authors were not able to match it with a standard powder

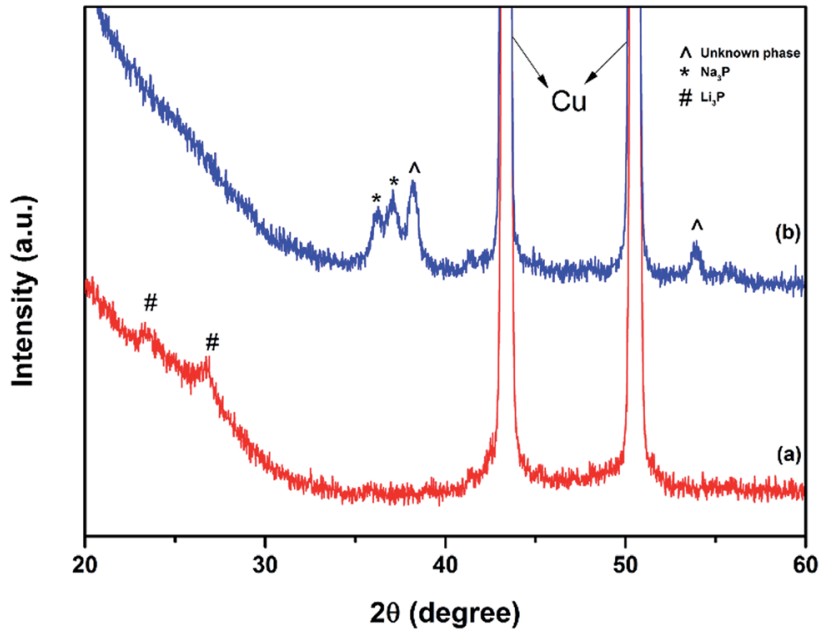

Fig. 8 Ex situ X-ray diffraction patterns of the electrodes discharged in lithium and sodium half-cells to $0.01 \vee$ vs. $\mathrm{Li}_{/} / \mathrm{Li}^{+}$and $\mathrm{Na} / \mathrm{Na}^{+}$, respectively: (a) composite $\mathrm{C}-1$ from a lithium cell (b) composite $\mathrm{C}-1$ from a sodium cell. The background at $20-30^{\circ}$ is due to the Kapton tape used to protect the sample. 
diffraction record, possibly due to the limited available diffraction data on sodium-phosphorus compounds.

The presence of two phases in the XRD pattern is consistent with the fact that the initial capacity of the C-1 electrode in a sodium half-cell was well below the expected value for the electrode. Indeed, based on the assumption of the reversible transformation between $\mathrm{P}$ and $\mathrm{Na}_{3} \mathrm{P}$ and the expectation of the capacity of carbon component of about $100 \mathrm{~mA} \mathrm{~h} \mathrm{~g}^{-1}$ (measured independently), the expected capacity of the C-1 electrode in a sodium half-cell was $1847 \mathrm{~mA} \mathrm{~h} \mathrm{~g}{ }^{-1}$. However, the first discharge capacity of the cell was only $1530 \mathrm{~mA} \mathrm{~h} \mathrm{~g}^{-1}$. We estimate that not more than 2.4 sodium ions per one phosphorus atom (instead of 3 sodium ions) got incorporated into the electrode during the first discharge of the half-cell. Interestingly, our results with electrodes incorporating black phosphorus are somewhat different from those by Yabuuchi et al. ${ }^{21}$ who have observed a single $\mathrm{Na}_{3} \mathrm{P}$ phase forming in amorphous phosphorus-carbon electrodes by synchrotron XRD. Their experiment was, however, conducted with thinner electrodes. Also, differences between the reaction mechanisms of amorphous phosphorus and black orthorhombic phosphorus are possible. Kim et al. have also presented an ex situ XRD pattern of a discharged electrode. ${ }^{18}$ Two features were resolved in the range of $35-38^{\circ}$ in the pattern (Fig. $3 \mathrm{~b}$ in ref. 18) and were assigned to be peaks of $\mathrm{Na}_{3} \mathrm{P}$. We note however, that the righthand side peak is noticeably shifted from the expected position of $\mathrm{Na}_{3} \mathrm{P}$ while the left-hand side feature is unusually broad. It is, in our view, possible that the two peaks of $\mathrm{Na}_{3} \mathrm{P}$ were not resolved in their experiment and were recorded as one broader feature. Consequently, the right-hand side peak may belong to the same unexpected phase we observe at about $38^{\circ}$ (Fig. $8 \mathrm{~b}$, this work).

Fig. 9 depicts SEM images of the as-prepared C- 1 and C-2 electrodes as well as SEM images of the electrodes cycled in lithium and sodium half-cells. As-prepared electrodes C-1 and C-2 are shown in Fig. 9a and b. There are no visible cracks on the surface of both electrodes. The electrodes cycled within the potential window of $2.0-0.01 \mathrm{~V} v s$. $\mathrm{Li}^{2} \mathrm{Li}^{+}$for a large number of cycles (Fig. 9c and d) are obviously damaged, displaying signs of deformation and disintegration, accompanied by delamination from the current collector. The cycled electrodes are also covered by a kind of film (this is particularly obvious in Fig. 9c), which we assign to the solid electrolyte interface or polymeric layers formed through the polymerisation of the electrolyte solvents. Fig. 9d also directly shows areas with the exposed copper current collector (marked by placing white elliptical markers on the corresponding areas) due to the delamination of the electrode's active layer. Similar electrode evolution after significant cycling in the broad potential window $(2.0-0.01 \mathrm{~V} v s$. $\mathrm{Na} / \mathrm{Na}^{+}$) was detected for the electrodes extracted from sodium half-cells. The performance of the electrodes degrades gradually due to their mechanical disintegration and, possibly, the insulating nature of the organic layers that build up on the electrode (contribution from such a mechanism is widely suggested for the $\mathrm{Si}$ anodes for Li-ion batteries).

Fig. 9e and $\mathrm{f}$ shows the SEM images of the $\mathrm{C}-1$ and $\mathrm{C}-2$ electrodes cycled within a restricted potential window of 2.0-
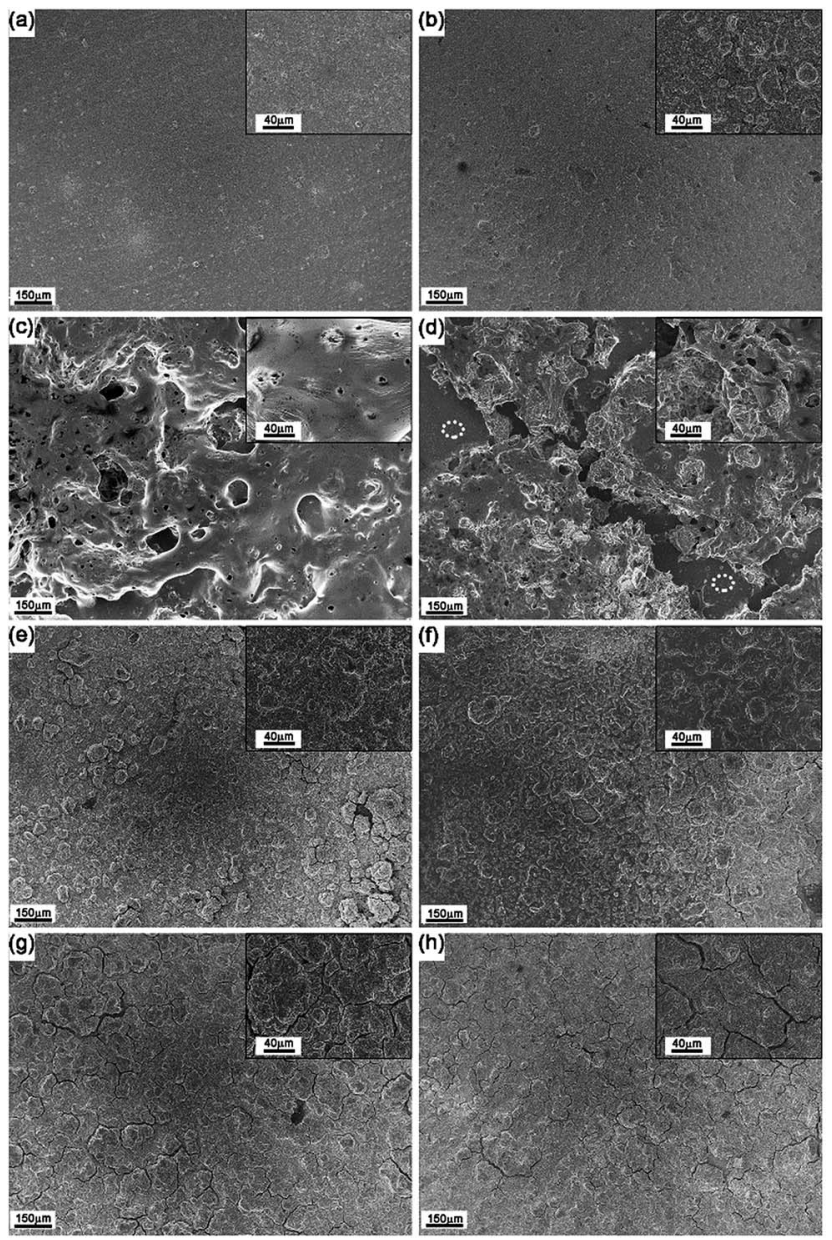

Fig. 9 SEM images of the C-1 and C-2 composite electrodes before and after cycling in lithium and sodium half-cells: ( $a$ and $b$ ) as-prepared electrodes for the composites C-1 and C-2, (c and d) C-1 and C-2 electrodes cycled in lithium half cells within the potential window of 2.0-0.01 V vs. Li/Li for 150 cycles, (e and f) C-1 and C-2 electrodes cycled in lithium half-cells within a restricted potential window of 2.0$0.67 \mathrm{~V}$ vs. $\left(\mathrm{Li} / \mathrm{Li}^{+}\right)$for 70 and 62 cycles, respectively, (g and h) C-1 and $\mathrm{C}$-2 electrode cycled in sodium half-cells within a restricted potential window of $2.0-0.33 \mathrm{~V} v \mathrm{vs}$. Na/ $\mathrm{Na}^{+}$for 100 cycles. An inset in each case shows a higher magnification image of the corresponding electrode.

$0.67 \mathrm{~V}$ vs. $\mathrm{Li} / \mathrm{Li}^{+}$. The surfaces of the electrodes retain their shapes and look similar to the surfaces of the as-prepared electrode with the exception of the some minor cracks and an increased roughness of the surfaces. The C-1 and C-2 electrodes cycled in sodium half-cell within a potential window of 2.0-0.33 $\mathrm{V} v$ s. $\mathrm{Na} / \mathrm{Na}^{+}$display similar appearance (Fig. $9 \mathrm{~g}$ and $\mathrm{h}$ ).

The major difference with the lithium cells is more pronounced cracking in the electrode, possibly due to a larger expansion of the film upon sodium insertion. Another interesting observation is a reduced formation of gel-like polymeric layers on the electrodes in sodium cells, which can be correlated with a different solvent (PC) and the presence of FEC as a stabilising additive. Despite some cracking, the electrode films retain good overall stability. We suggest that, similarly to the reactivity with lithium, the volume change in the electrode is reduced when the bottom cut-off potential is restricted to 0.33 
vs. $\mathrm{Na} / \mathrm{Na}^{+}$in sodium cells, leading to an improved stability of the electrode and attractive cyclic stability demonstrated in Fig. 7.

\section{Conclusions}

In summary, nanocomposites of black (orthorhombic) phosphorus with carbon have been evaluated in this report. It is found that, based on the use of a particular ball milling unit, composites with either nanoparticles of black phosphorus or well-dispersed phosphorus in a significantly disordered state can be manufactured. The composites have been subsequently assessed in both lithium and sodium electrochemical half-cells. It is found that the composites can display impressive initial capacities at the level of approximately 1700 and $1300 \mathrm{~mA} \mathrm{~h} \mathrm{~g}{ }^{-1}$ (per total weights of the composites) for lithium and sodium cells, respectively, and the capacity gradually deteriorates when the cycling is performed within potential windows of $2.0-0.01 \mathrm{~V} v s$. $\mathrm{Li} / \mathrm{Li}^{+}$or $\mathrm{Na} / \mathrm{Na}^{+}$. The composite with crystalline nanoparticles of black $\mathrm{P}$ displays a better cyclic stability. Attractive stable cyclic performances at the level of 700 (lithium cells) and 350-400 $\mathrm{mA} \mathrm{h} \mathrm{g}^{-1}$ (sodium cells) can be observed if the potential windows are restricted to 2.0-0.67 vs. $\mathrm{Li} / \mathrm{Li}^{+}$and $2.0-0.33 \mathrm{~V}$ vs. $\mathrm{Na} / \mathrm{Na}^{+}$. Ex situ XRD and SEM analyses have been performed to provide insights into the charge storage and failure mechanisms of electrodes. The XRD studies demonstrate that the redox chemistry of phosphorus in lithium half-cells is based on the reversible transformation to the $\mathrm{Li}_{3} \mathrm{P}$ phase while the transformation to $\mathrm{Na}_{3} \mathrm{P}$ phase in sodium half-cells is incomplete, leading to a smaller than expected practical capacity observed in the experimental tests. The post-cycling SEM studies reveal that electrodes gradually disintegrate and delaminate from current collectors when the electrochemical testing is done within larger potential windows of $2.0-0.01 \mathrm{~V}$ vs. $\mathrm{Li} / \mathrm{Li}^{+}$or $\mathrm{Na} / \mathrm{Na}^{+}$. Such an effect is absent for the restricted potential windows of 2.0-0.67 vs. $\mathrm{Li} / \mathrm{Li}^{+}$and $2.0-0.33 \mathrm{~V}$ vs. $\mathrm{Na} / \mathrm{Na}^{+}$, leading to stable cyclic performances for all tested electrodes in these restricted potential windows.

\section{Acknowledgements}

Financial support from Central Research Grants Scheme of Deakin University and a Discovery grant of the Australian Research Council is acknowledged. The Australian Research Council is also acknowledged for funding Deakin University's Magnetic Resonance Facility, JEOL JEM-2100F transmission electron microscope and combined FTIR/Raman microspectroscopic instrument through LIEF grants LE110100141, LE100100195 and LE120100166. The authors thank Timcal Ltd. for providing a sample of Super $\mathrm{P} \mathrm{Li}^{\mathrm{TM}}$ carbon black and acknowledge the use of facilities in the Victorian Node of the Australian National Fabrication Facility (ANFF).
2 R. Hultgren, N. S. Gingrich and B. E. Warren, J. Chem. Phys., 1935, 3, 351.

3 C.-M. Park, J.-H. Kim, H. Kim and H.-J. Sohn, Chem. Soc. Rev., 2010, 39, 3115.

4 C. Marino, A. Debenedetti, B. Fraisse, F. Favier and L. Monconduit, Electrochem. Commun., 2011, 13, 346.

5 C. M. Park and H. J. Sohn, Adv. Mater., 2007, 19, 2465.

6 M. C. Stan, J. v. Zamory, S. Passerini, T. Nilges and M. Winter, J. Mater. Chem. A, 2013, 1, 5293.

7 L.-Q. Sun, M.-J. Li, K. Sun, S.-H. Yu, R.-S. Wang and H.-M. Xie, J. Phys. Chem. C, 2012, 116, 14772.

8 J. Qian, D. Qiao, X. Ai, Y. Cao and H. Yang, Chem. Commun., 2012, 48, 8931.

9 C. Marino, L. Boulet, P. Gaveau, B. Fraisse and L. Monconduit, J. Mater. Chem., 2012, 22, 22713.

10 M. Nagao, A. Hayashi and M. Tatsumisago, J. Power Sources, 2011, 196, 6902.

11 L. Wang, X. He, J. Li, W. Sun, J. Gao, J. Guo and C. Jiang, Angew. Chem., Int. Ed., 2012, 51, 9034.

12 W.-J. Zhang, J. Power Sources, 2011, 196, 13.

13 J. Sun, G. Zheng, H.-W. Lee, N. Liu, H. Wang, H. Yao, W. Yang and Y. Cui, Nano Lett., 2014, 14, 4573.

14 V. L. Chevrier and G. Ceder, J. Electrochem. Soc., 2011, 158, A1011.

15 Y. Xu, Y. Zhu, Y. Liu and C. Wang, Adv. Energy Mater., 2013, 3, 128.

16 Y. Xu, J. Guo and C. Wang, J. Mater. Chem., 2012, 22, 9562.

17 A. Darwiche, C. Marino, M. Sougrati, B. Fraisse, L. Stievano and L. Monconduit, J. Am. Chem. Soc., 2012, 134, 20805.

18 Y. Kim, Y. Park, A. Choi, N.-S. Choi, J. Kim, J. Lee, J. H. Ryu, S. M. Oh and K. T. Lee, Adv. Mater., 2013, 25, 3045.

19 J. Qian, X. Wu, Y. Cao, X. Ai and H. Yang, Angew. Chem., Int. Ed., 2013, 52, 4633.

20 W.-J. Li, S.-L. Chou, J.-Z. Wang, H.-K. Liu and S.-X. Dou, Nano Lett., 2013, 13, 5480.

21 N. Yabuuchi, Y. Matsuura, T. Ishikawa, S. Kuze, J.-Y. Son, Y.-T. Cui, H. Oji and S. Komaba, ChemElectroChem, 2014, 1, 580 .

22 A. Calka and A. P. Radlinski, Mater. Sci. Eng., A, 1991, 134, 1350.

23 T. Ramireddy, M. M. Rahman, T. Xing, Y. Chen and A. M. Glushenkov, J. Mater. Chem. A, 2014, 2, 4282.

24 S. Reich and C. Thomsen, Philos. Trans. R. Soc., A, 2004, 362, 2271.

25 T. Xing, L. H. Li, L. Hou, X. Hu, S. Zhou, R. Peter, M. Petravic and Y. Chen, Carbon, 2013, 57, 515.

26 A. C. Ferrari, Solid State Commun., 2007, 143, 47.

27 A. Bytchkov, F. Fayon, D. Massiot, L. Hennet and D. L. Price, Phys. Chem. Chem. Phys., 2010, 12, 1535.

28 S. Lange, P. Schmidt and T. Nilges, Inorg. Chem., 2007, 46, 4028.

\section{Notes and references}

1 Chemistry of the Elements, ed. N. N. Greenwood and A. Earnshaw, Butterworth Heinemann, 1997. 